\title{
Self-Learning Skills Perceived in Communities of Inquiry of Portuguese Higher Education Students
}

\author{
José António Moreira ${ }^{1}$, António Gomes Ferreira², Ana Cristina Almeida ${ }^{2}$ \\ ${ }^{1}$ Department of Education and Distance Teaching, Open University, Lisbon, Portugal \\ ${ }^{2}$ Faculty of Psychology and Educational Sciences, University of Coimbra, Coimbra, Portugal \\ Email: jmoreira@uab.pt, antonio@fpce.uc.pt, calmeida@fpce.uc.pt
}

Received December $16^{\text {th }}$, 2012; revised January $19^{\text {th }}, 2013$; accepted February $18^{\text {th }}, 2013$

\begin{abstract}
Copyright (@ 2013 José António Moreira et al. This is an open access article distributed under the Creative Commons Attribution License, which permits unrestricted use, distribution, and reproduction in any medium, provided the original work is properly cited.
\end{abstract}

\begin{abstract}
The purpose of this study was to report evidence obtained in Communities of Inquiry (CoI) as framed by the work of Garrison, Anderson and Archer (2000) that was carried out in different groups, and identify the emergent learning skills of its students. The study comprised 510 undergraduate students enrolled in blended online courses offered through Moodle platform during one semester. It considered students from different Portuguese schools, of University and Polytechnic in Health, Education and Psychology Courses. Moreira and Almeida (2011) have suggested that CoI framework is a valid, reliable, and efficient measure of its dimensions within the Portuguese population. Assuming the CoI survey as a useful evaluation tool for providing feedback about the effectiveness of online courses in the construction of effective learning communities, we've studied the skills students recognize they acquire in virtual environments of learning, using the adapted Self-Learning Competence Scale (Lima-Santos, Rurato, \& Faria, 2000). We've concluded that in both institutions, University and Polytechnic, relevant learning experiences have been fostered, towards the emergence of communities of inquiry, in which the students perceived that they have developed self-learning competences.
\end{abstract}

Keywords: Higher-Education; Self-Learning Skills; Community of Inquiry; Online Learning

\section{Introduction}

Nowadays, the large number of students per class and the traditional methods of teaching are hardly compatible with one of the most fundamental requirements of higher education which is the skills training. This indicates that the current methods of teaching and the role of both teachers and students must be reframed. Students are expected to acquire knowledge, gain practice and develop their competences. More and more the usage of technological tools as a support to the teaching presence begins to flourish as a source of continued cognitive, social and dialogical presence in the learning process. Teachers may guide the instructional process by being present and coping with the pedagogical relationship in a blended web-based learning. However, such helpful resources must convey a paradigm that settles a relational climate to an effective educational experience. So, the need for a community is imperious, specifically one of inquiry, in order to promote learning skills and knowledge in a constructivist and collaborative ambience. Such an atmosphere is convenient for the groundwork of professionals that are expected to be autonomous, active and effective in performing their functions (Garrison, Anderson, \& Archer, 2000).

The CoI framework is a process model that provides a comprehensive theoretical frame that can support both the research on online learning and the practice of online instruction. It assumes that effective online learning requires the development of a community (Thompson \& MacDonald, 2005; Shea,
2006; cf. Swan et al., 2008) that supports meaningful inquiry and deep learning. The importance of this matter is revealed by the fact that it will be the young people of today that will assume in the future important roles in the political, social and cultural life of the world community.

In this context, the study we have developed aims to understand the workability of the CoI model, while examining its effects in self-learning skills. To this end, we aim to explore possible relationships between face-to-face instructions, fostering a valuable pedagogical relationship providing key elements central to a collaborative learning environment, and an online teaching model enabling the creation of learning communities.

\section{Self-Learning Skills and the CoI Model}

The concept of learning skills under analysis is a predictive variable of the academic relation, associated to openness towards the learning opportunities, made possible by day-to-day experiences, and the ability to effectively use these formal and informal experiences. So, to engage in learning is to awaken within the self such skills as self-reliance, self-responsibility, self-confidence in pursuing goals and active participation in various social contexts, qualities that are required in all walks of life (Nyhan, 1996).

As we know, the ability to learn by oneself is now an essential requirement for school achievement. An independent student is one who can identify a need for learning and uses its personal resources effectively, using cognitive, social and crea- 
tivity skills in a systematic and flexible way (Faria, Rurato, \& Lima Santos, 2000).

The Recommendation of the European Parliament and Council of the European Union (2006) on key competences for lifelong learning states that the ability to learn is the basis of all learning. Along with seven others, viewed as the combination of knowledge, aptitudes and attitudes suited to the context, they are needed for the achievement and development of all people, for the exercise of active citizenship, social inclusion and employment. The remaining core competences identified are: communication in mother-tongue, knowledge of foreign languages, mathematical competence and basic competences in science and technologies, digital competence, social and civic competence, sense of initiative and entrepreneurship, cultural awareness and expression. Now, students who learn to learn independently, in a community and using IT tools are able to activate core competences while dealing with school contents, while expressing themselves and applying knowledge to problem situations with which they are confronted.

Still following the Recommendation text, on the explanation of learning to learn as being the "ability to pursue and persist in learning, including through effective management of time and information, both individually and in groups. (...) including also the awareness of one's learning process and needs, identifying available opportunities, and the ability to overcome obstacles in order to learn successfully... (Official Journal of the European Union, 2006, L394/16).

This notion is close to the competence that authors such as Rurato (2008) calls self-learning, i.e., key and core qualification that implies that each individual has its own awareness, motivation, confidence and ability to learn continuously. In order to learn to learn, student have to know the strengths and weaknesses of their skills and qualifications, know and understand their preferred learning strategies and be able to seek available formative and support opportunities. The individual should be able to dedicate time to learn independently and be self-disciplined, but also to learn as a team, taking advantage of the benefit of working with a heterogeneous group and sharing knowledge acquired in a group (European Parliament and Council of the European Union, 2006).

Indeed, the ability to learn by oneself is a basic human capacity, which becomes an essential requirement for living in today's world, self-learning becoming a way of life. However, it should be noted that learning to learn requires intention, effort, discipline and responsibility, not to be confused with simplicity, laid-back attitude or shallowness of the learning process (Lima Santos \& Gomes, 2009).

More than learning, learning to learn is an important means to progress, for enrichment and personal and social well-being. This regulatory and controlled dimension to promote the ability to compete, cooperate and act is more and more decisive for the individual and society, due to the knowledge that they have accessed, built and mobilised (Lima Santos, Rurato, \& Faria, 2000). The Recommendation in the Official Journal of the European Union (2006) further states that this competence implies not only that an individual should be able to access, process and assimilate new knowledge and skills, but also know how to seek guidance or advice. Learning to learn requires the acquisition of basic core competences, such as literacy and numeracy, scientific thought, command of the mother-tongue and other languages; but the management of knowledge, skills and attitudes also requires self-control and monitoring of proc- esses to achieve expected results. However, this learning "style" is often prior to and continued after formal learning contexts. Rurato (2008) corroborates the idea that the self-learning competence applies to both traditional and formal learning situations and informal learning experiences provided by dayto-day situations. The author points out that individuals who have this competence view learning as a natural, everyday experience and are able to explore opportunities by effectively using formal and structured teaching experiences, while benefiting from multimedia transmission systems and open learning (Rurato, 2008).

Currently, the term self-learning appears in online learning environments often associated to an educational philosophy of student-centred learning. In other words, the relationship between self-learning and the educational model proposed is vast and flexible, enabling various ways of conducting the process, either face-to-face or distance (Alonso, Manrique \& Viñes, 2005). The focus on self-learning places the student, the learning goals and contents in direct relation, and separates the student at the center of the process of the external educational agents.

To engage in self-learning is to awaken the capacity of selfsufficiency, self-responsibility, self-confidence in the ability to achieve goals and participate actively in various contexts (Lima Santos, Rurato, \& Faria, 2000).

Magalhães (2011) also states that self-learning must be defined as the ability to learn in a pro-active, responsible and independent way, in the sense that the student (re)builds its own learning pathway, chooses the contents to be acquired and selfregulates the learning process (although not necessarily alone).

More than a process through which students can gain knowledge, be educated and study independently based on the available contents, self-learning can allow learners to learn in an active, independent and responsible way, learning at their own pace and development; learn at their own initiative, steering their own learning process; update and renew their knowledge and skills according to their needs; build their knowledge that will enable them to deal with future challenges, and value and complement their training (Rurato, 2008).

So, based on these assumptions, we believe it is crucial to invest in strategies that promote the sense of learning competence. The study of the sense of competence in higher education students is particularly relevant in this phase, and mostly in the early years, because young adults face various personal and external challenges that test their internal resources and the ability to deal with ambiguity and uncertainty. Being a less structured learning context and showing less constraints than other learning contexts, higher education requires students to have a greater degree of self-regulation that enhances the expression of differences in motivation and self-learning. In fact, in this period there seem to be more chances of exploring alternatives, making investments and increasing knowledge of oneself and one's abilities. The goal is, therefore, to learn to use personal resources effectively and maximize them, using cognitive, social and creativity abilities in a flexible way.

In the pedagogical relationship, guidelines provided by the teacher-tutor facilitate personal constructs and shared learning. As such, our reference conceptual framework is the already mentioned Community of Inquiry (CoI).

The Community Inquiry framework (Arbaugh et al., 2008; Garrison \& Anderson, 2003; Swan et al., 2008) is considered one of the most promising schemes of modeling online teaching. As a broad and integrated model, it explains successful teaching, 
allowing the research and the monitoring of learning processes in a collaborative, interactive and constructivist approach. The underlying idea of the model is that an educational Community of Inquiry is a group of individuals who collaboratively engage in purposeful critical discourse and reflection to construct personal meaning and confirm mutual understanding (Garrison \& Anderson, 2003). In this sense, successful learning stems from three critical elements which interact with each other and are mutually influenced: the cognitive presence, the social presence and the presence of teaching. Taking into account the vast literature defining these elements (e.g., Swan et al., 2008), we are interested in testing our own educational experience. In other words, to verify if in the teaching process we designed such a structure and organization that encourages a diversity of perspectives that promote research, criticism and creativity in a collaborative environment of learning.

In the end, we wish to foster learning communities of inquiry, preparing our students to be responsible and to look for the meaning of their own educational experience, by self-regulation and conscientious control through negotiation of meanings with the community.

\section{Context of Study}

\section{Participants and Pedagogical Models Principles}

Based on the assumptions of the theoretical model and on previous exploratory work on the CoI framework (cf. Garrison, Anderson, \& Archer, 2000), we expect that for all the groups of students surveyed, the three presences-cognitive, social and teaching —arise distinctly but are overlapping or related to each other.

The participants in this study are undergraduate students ( $\mathrm{n}=$ 510) enrolled in blended online courses during the school year of 2010/2011, offered through Moodle platform during one semester at different Portuguese schools (polytechnic private institute and public university). It involved students of a Higher School of Education, a Higher School of Health and a Faculty of Psychology and Educational Sciences, in courses such as Physical Education, Music Education, Basic Education, Physiotherapy, Radiology, Pharmacy, Clinical Analysis, and Psycho$\log y$.

In Portugal, both University and Higher Schools enable higher education, but they differ somewhat. The goal of training at polytechnic institutes is the creation, transmission and dissemination of culture, but mainly professional knowledge and practice. Universities are high-level institutions oriented to the creation, transmission and dissemination of culture, knowledge, science and technology through study, teaching, research, experimental development and provision of specialized services to the community. Thus, in universities the curricula is more theoretical, and the experimental stage of professional initiation is introduced in the last year of school.

Based mainly on the principles of constructivism, autonomy and interaction, we sought to develop a model taking as reference the view of Garrison, Anderson and Archer (2000) based on the development of skills and on student-centred learning. These were the principles that guided the organisation of education, the shaping of student and teacher's roles, the planning, design and management of learning activities, the definition of the types of materials to be developed and the nature of the assessment of skills acquired.

Student-centred degree programmes must be designed in such a way that learners will develop the particular mix of competences considered useful and necessary for the academic, professional and/ or vocational area (European Network of Information Centres in the European Region and National Academic Recognition and Information Centres in the European Union, 2010). The essential components of a degree are based on inter-related dimensions described by the following Dublin Descriptors: acquiring knowledge and understanding; applying knowledge and understanding; making informed judgments and choices; communicating knowledge and understanding; and capacities to continue learning.

In general, the skills to be developed by the end of first cycle involve the "capacity to learn; communication skills; team working skills; information technology skills; problem solving; autonomy; reflection skills; interpersonal skills; planning and time management; problem solving; decision-making; appreciation of diversity and multi-culturality; ethical commitment; critical and self-critical abilities; capacity to improve their own learning and performance, including the development of study and research skills; ability to analyze, synthesize, evaluate, to identify problems and work out solutions; firm knowledge of the profession in practice" (cf. Tuning Project, European Network of Information, 2010).

Thus, the student lies at the centre of this pedagogical model and is an active element who builds his knowledge, committed and engaged in the learning process and integrated in a community of learning. Overcoming the methods and instructional tasks, the different teaching situations, present in this model, are outlined according to the student and to a learning process that seeks to lead to the acquisition of skills necessary to live in the society of knowledge and to the specific skills related to the field chosen by the student.

In this model, learning takes place using either individual learning or using dialogue and interaction among peers and teachers through cooperative and collaborative learning strategies. Individual learning emerges from autonomous work completed by the student, based on activities, learning objectives, bibliography and guidelines provided by the teacher. On the other hand, collaborative learning emerges from joint work, sharing experiences and perspectives, based on common goals and work methods negotiated within the group. The creation and organisation of student groups serve to interpret the view that the construction of knowledge must be socially contextualized (Garrison \& Anderson, 2003). This model also defined a new role for the teacher, to the extent that more than being a source of information, the teacher becomes a guide, a facilitator of learning who encourages students to interact in the learning community. The teacher now becomes someone who encourages and accepts student autonomy and initiative; encourages students to talk with the teacher and to each other; encourages them to solve problems and ask each other the solution; stimulates them to take responsibility and stimulates discussion and keeps up the curiosity of students (Moreira \& Monteiro, 2010).

Another principle of the model is based on the rule of interaction. In the first generations of distance learning, interaction was essentially seen as student-content interaction and student-teacher interaction. On the other hand, this model extends those dynamics into a student-student interaction through the creation of discussion groups within each class, and each virtual classroom. This implies their previous planning and activation strategies of learning, in order to stimulate initiative and involvement of students, and to ensure their commitment, as well 
as to guide the nature of their work. Based on the ideals of Perret Clermont (1996), who states that the cognitive conflict created by social interaction is the locus in which the power that leads to intellectual development is generated, we sought to develop a model that promotes this social interaction and the consequent creation of learning communities or Communities of Inquiry (Garrison, Anderson, \& Archer, 2000).

Interactions are therefore shaped in this model as the practical basis of learning and are based on constructivist and sociointeractionist theories, as they require the negotiation of conflicts and sharing of meanings (Monteiro, 2011).

\section{Educational Environment Design}

\section{Development and Implementation of the Online Curricular Units}

Prior to the educational environment design of the curricular units Dynamics of the Contemporary World and the Evolution of the Portuguese Space and Theories and Models of Problem Solving, it was necessary to take into account some principles which may be generalized to the design of any curricular unit in an online environment, namely: 1) the design must focus on learning, aiming to achieve specific objectives, achievable and measurable; 2) it should focus on performance or meaningful achievements; 3) it must allow the results to be reliably and validly measured by developing the necessary performance evaluation instruments and 4) it must be empirical and self-correcting.

There were some structural components which were present in all the above mentioned curricular units. First, every curricular unit produced a Semester Teaching Guide (STG), which acted as the main reference to the student concerning the contents, structure and activities. In its design, we tried to establish a correct horizontal articulation among all its elements and a vertical intelligible articulation. A clear description of the learning purposes and objectives was also required, defined according to the students' expected achievements and not just content-focused. The STG also includes the learning resources that students should use (e.g. chapters, books and articles they should read and those they should refer to in order to deepen their knowledge; videos, images and websites related to the study topics), the activities to be carried out and the evaluation criteria. It is important to note that despite the specific guidelines of the STG, its implementation was never too strict. On the contrary, the principles of flexibility and adaptability, considered by Garrison and Anderson (2003) to be indispensable in constructivist environments were always present.

Secondly, resources/learning objects referring to diverse and attractive learning objectives were made available in the LMS. Current articles related to the themes discussed and online multimedia contents (in audio and video) were put at the students' disposal, aiming to motivate them and to create a bond between students and the teacher.

Thirdly, there was a great concern about the development of tasks to be undertaken by students, i.e., focusing the whole process on problems students must solve and, consequently, developing learning experiences (individual and collaborative).

Fourthly, the structuring element of the whole educational process: the stimulation of virtual classrooms (forums) through asynchronous communication. We consider this as a determinant and structuring element of the whole process. As a result, in all topics of the curricular units, it was our concern to pro- mote ongoing asynchronous communication in the virtual classrooms, through three types of communicational standards: 1) student(s)-content interaction, 2) student(s)-teacher interaction and 3) student(s)-student(s) interaction. The forum was the privileged mean of communication to allow the debates to take place between students and the senior e-teacher.

Finally, and not necessarily in this order, we have selected the theories and models that we considered the most appropriate ones. From the pedagogical point of view, we based ourselves on the conceptual models congruent with the constructivist learning models we stand for. Thus, among these models we have selected, for its up-to-datedness, adaptability and pertinence, the problem solving models of Jonassen (1999) Constructivist Learning Environments, and the Community of Inquiry model developed by Garrison, Anderson and Archer (2000).

\section{Methodological Aspects}

\section{Participants}

The subjects of this study were 510 undergraduate students, $338(66.3 \%)$ female and 172 (33.7\%) male students, enrolled in higher schools and universities, public and private, taking blended online courses offered through Moodle platform during one semester of the 2010/2011 school year. This study involved Portuguese Health, Education and Psychology students. Among this universe, 150 (29.4\%) were Psychology students, 182 (357\%) students of Health courses and 178 (349\%) students of Education. 150 (294\%) of those students attended public University, 162 (318\%) private University and 198 (38.8\%) private Higher Schools of Polytechnic Institutes. The students are aged between 17 and 60 years old, but mostly between 17 and 34 years old (59.8\% of the respondents are in the 17 - 24 age group, and $248 \%$ in the 25 - 34 age group).

\section{Instruments}

The instrument used to study the learning community in all three teaching environments was the Community of Inquiry Survey of Garrison et al. (2000) properly translated and adapted. Like the original, the survey instrument contains a random sequence of 34 items of the ten categories of factors combining combine the three elements that need to be present in any desirable learning context, as they are distributed in the coding template (Table 1, cf. Garrison \& Anderson, 2003). Students were asked to indicate their degree of agreement with each item (from Strongly Disagree to Strongly Agree) on a five-point Likert scale.

The 34 item instrument was implemented in three institutions in the school year of 2010-2011, with singularities (e.g., public $v s$. private school institution) and common features such as the lecturing of identical courses. The sample criterion was to recruit students whose teachers were tutoring online learning settings through the Moodle platform.

In turn, the instrument used to assess the skills of self-learning was the Self-Learning Competence Scale (Lima Santos, Rurato \& Faria, 2000), with its 24 items adapted to online environments, for which the authors have granted their permission, given the relevance of self-learning studies in these "new" environments.

The Self-Learning Competence Scale-SLCS consists of 24 
Table 1.

Community of inquiry coding template.

\begin{tabular}{ccc}
\hline Elements & Categories & Indicators (examples) \\
\hline Triggering event & Sense of puzzlement \\
Cognitive presence & Exploration & Information exchange \\
& Integration & Connecting ideas \\
& Resolution & Apply new ideas \\
Affective expression & Emotions \\
Social presence & Open communication & Risk-free expression \\
& Group cohesion & Encouraging collaboration \\
Teaching & Design \& organization & Defining/initiating discussion topics \\
presence & Facilitation & Sharing personal meaning \\
& Direct instruction & Focusing discussion \\
\hline
\end{tabular}

items, each rated on a 5-point Likert-like scale in which "1Totally Disagree" indicates low competence and "5-Totally Agree" indicates high competence, showing the degree of each individual's self-characterisation in each field of competence. The SCLS items are organised in three general dimensions: 1) Active Learning or Accepting Personal Responsibility through Learning; 2) Learning Initiative and Guidance to Experience; and 3) Learning Autonomy.

\section{Outcomes}

\section{What the CoI Survey Reveals about the Communities of Inquiry Instituted}

Each student answered the survey questionnaire at the end of the course. During the courses, each teacher created his/her own dynamics, fostering knowledge and pedagogical relationships through web mediation, particularly online forums. Ordinal responses were scored using a 1 - 5 point-scale (from Strongly Disagree to Strongly Agree). After statistic data processing, we observed that mean responses for all the 34 items ranged from 3.74 to 4.24 , with a global median of 3.98 and a variance of 0.016 . Standard deviation ranged from 0.66 to 0.89 .

The Shapiro-Wilk test of normality showed that none of the analyzed variables presented a normal distribution along the 34 items, all of them with a negative skewness. Looking at the descriptive statistics we can situate the central measures around point 4, which reveals that, in general, students agreed that they belong to a community of inquiry in all the indicators considered.

In order to understand if the three groups, taking into consideration their different fields of study, differed about the way they perceive themselves in the process and environment of learning, we used the non-parametric Kruscall-Wallis test. Through an analysis "of variance" by ranks, we found the aggregate degree to which the groups differ. The Psychology students' group was the highest, ranking only in 5 items that have in common a social dimension of learning in the community (e.g., "I was able to form distinct impressions of some course participants", "I utilized a variety of information sources to explore problems posed in this course”, "I felt comfortable inter- acting with other course participants", "I felt that my point of view was acknowledged by other course par ticipants", “The instructor encouraged course participants to explore new concepts in this course”).

The group formed by Health students highlighted their sense of participation in the inquiry community in other 5 items. All of them dealt with instruction supported by communication: ("I felt comfortable conversing through the online medium”, "Brainstorming and finding relevant information helped me resolve content related questions", "The instructor clearly communicated important course topics”, “... clearly communicated important course goals”, “... provided feedback in a timely fashion").

In all the other items, the group of Education students scored the highest, differing significantly in measures assembling most of the items. Since they are studying to become teachers, we may speculate that perhaps they are more aware of the importance of a learning community. At the same time, they are learning to be teachers following a model (White \& Frederiksen, 1998) to implement and guide the teaching procedures with an online component.

We also used non-parametric tests to study how variables of the theoretical model of learning communities intended for online or blended learning behave in terms of cognitive, teaching and social presences and how often they occur. This way, we expected to infer the probability that a particular event may occur again. In that sense, on-line teaching allows the students to better learn, equate and discuss subject matters aiming to construct their academic development.

After we verified that all the 34 items were highly and significantly correlated, conditions were in place to produce a model so that the various items share common factors.

The Kaiser-Meyer-Olkin Measure of Sampling Adequacy test with $\mathrm{KMO}=0.968$, indicates a very good measure of the adequacy of the variables to enter the model. And Bartlett's sphericity tests the hypothesis that the correlation matrix is not the identity matrix $\left(\chi^{2}=10,758,380\right.$, df 561, $\left.p<0.001\right)$.

Taken together, these tests provide a minimum standard which should be addressed before a principal components analysis (or a factor analysis) is conducted. Principal components analysis is a method of data reduction, aiming to reduce the 34 
measures to a few principal components. The purpose of the exploratory factor analysis was to assess the underlying structure of the CoI instrument used to measure the three elements after an online learning experience.

There were four factors with Eigen values greater than one. The exploration of the underlying structure of the variables rotating the four factor solutions obtained revealed the interpretability of a simple structure evidenced by the intertwining of the factors. Therefore, looking for the best correspondence to the theoretical model, we chose a three-factor oblimin solution. We expect it to be the best solution since the three factors of the community of inquiry are seen to be overlapping. Neither the cognitive nor the social or the teaching elements could exist without the others in an accurate experience of learning, even if it is partially online web learning. So, taking into account the assumptions of the theoretical model and previous exploratory work, we used principal component analysis with oblimin rotation to confirm the three elements. We expect them to be considered distinct but overlapping.

The three components extracted accounted for $55.6 \%$ of the total variance.

Hence, we can see that the relevance of principal components analysis is to redistribute the variance in the correlation matrix (using the method of Eigen value decomposition) in order to redistribute the variance to the first components extracted.

These results reflect the Pattern Matrix generated by the previously described principal component analysis. In support of this analysis, loadings for the Structure Matrix differed slightly, however both output matrices support the 3-factor model. There are 18 items loading most heavily on Factor 1, 9 items loading most heavily on Factor 2, which is consistent with the Teacher Presence and, finally, 4 items loaded most heavily on Factor 3.

The interpretability of those factors in line with the framework and design of the instrument, as to how student perceive the cognitive presence concerning the construction of meaning and understanding subject matters, encompasses the ability of participants to come together for a common purpose. Additionally, the asynchronous virtual community in which students interact may demand a significant teaching presence to manage and monitor the cognitive and social dynamic and to create a purposeful community of inquiry. This requires recognizing the unique features to achieve educational experiences through the three overlapping areas as the extraction procedures show, producing 8 iterations.

Reliability of the factors (Cronbach's alpha) was high and acceptable, yielding internal consistencies equal to 0.93 for Teaching Presence, 0.91 for Cognitive Presence, and 0.89 for Social Presence (see Table 2).

In addition to the fact that Cronbach's alpha measures high internal consistency for each presence of a set of items, enforcing substantive arguments that the respective items measure the underlying (or latent) construct, we have checked the unidimensionality for each Presence assumed under the educational purpose of the courses through exploratory factor analysis. We verified that for each Presence only one component was extracted.

For the Cognitive Presence factor, loadings in the component matrix ranged from 0.632 to 0.769 and the Eigen value for the first factor is larger than the Eigen value for the next factor (6.1 vs. 0.91). Additionally, the first factor accounts for $51.3 \%$ of the total variance. This suggests that the scale items are unidimensional.
For the Teaching Presence factor, loadings in the component matrix ranged from 0.677 to 0.796 . The initial Eigen value for the first factor is 7.1 versus 0.91 , accounting for $55.2 \%$ of the total variance.

For the Social Presence, 53.4\% of the total variance was explained by the first component with an Eigen value of 4.8, also greater than the subsequent one, with an initial Eigen value of 0.8. So, Teaching and Social Presences are also uni-dimensionally scaled.

Being the reliable scale made up of items measuring autonomous Presences, the next step was to observe the scores in each presence (responsive to the framework) and to compare the students by group. This regarded how they assumed the cognitive, social and teaching presence, when they learn from a web platform resource.

Considering the total sample of 510 students, Cognitive Presence items yielded a mean score of 3.93 (s.d. = 0.52), and ranged from 1.7 to 5 points in the agreement scale. Teaching Presence items yielded a mean score of 4.11 (s.d. $=0.56$ ), with a minimum score of 2 and a maximum score of 5. Social Presence items collectively yielded a mean score of 3.86 (s.d. = $0.58)$, ranging from 1.1 to 5 points.

On average, all the groups of students score Presences near point 4 of the scale (see Table 3 ). This suggests that all the three Presences, both individually and jointly, reveal that students group themselves in communities, in order to perceive themselves as being cognitive and socially present in the learning process.

However, there were differences in the scores obtained that suggest the usage of Kruskal-Wallis one-way analysis of variance by ranks. Using this non-parametric method we tested whether samples of students from different courses and different Higher Education institutions originate from the same distribution. The factual null hypothesis is that the populations from which the samples originate have the same median.

Test statistics K-M taking as grouping variable the institution presents $\chi^{2}=7.886(p<0.05)$ in respect to the global CoI. Taking into account the respective mean ranks, we can read this data as indicating that the public University is a less consistent community of inquiry. Looking for differences among the Presences, we found that only at the Teaching Presence level do those institutional origins differ $\left(\chi^{2}=10.898, p<0.01\right)$. This result is confirmed after comparing Public vs. Private polytechnic institutions using the Mann-Whitney test.

Using the course as the grouping variable in the K-M test, we observed that Psychology students were the lowest ranked ones. They revealed significant differences from the students of the other courses in the global CoI $\left(\chi^{2}=9.22, p=0.01\right)$, in the

Table 2.

Reliability coefficients (Cronbach's alpha) of each factor and of total CoI survey.

\begin{tabular}{ccc}
\hline Factors & Alpha & No. of items \\
\hline Cognitive presence & 0.913 & $\mathbf{1 2}$ \\
Social presence & 0.890 & $\mathbf{9}$ \\
Teaching presence & 0.932 & $\mathbf{1 3}$ \\
Total CoI & 0.964 & $\mathbf{3 4}$ \\
\hline
\end{tabular}


Table 3.

Descriptives for each presence of the CoI survey by group of students.

\begin{tabular}{|c|c|c|c|c|}
\hline & & \multicolumn{3}{|c|}{ Course } \\
\hline & & $\begin{array}{c}\text { Psychology } \\
\text { (Pub_Univ) } \\
\mathrm{N}=150\end{array}$ & $\begin{array}{c}\text { Health } \\
\text { (Priv_Polytech) } \\
\mathrm{N}=182\end{array}$ & $\begin{array}{c}\text { Education } \\
\text { (Priv_Polytech) } \\
\mathrm{N}=178 \\
\end{array}$ \\
\hline \multirow{4}{*}{$\begin{array}{l}\text { Cognitiv. } \\
\text { presence }\end{array}$} & Min & 2 & 2 & 2 \\
\hline & Max & 5 & 5 & 5 \\
\hline & Mean & 3.83 & 3.94 & 4.00 \\
\hline & Std.D & 0.54 & 0.52 & 0.49 \\
\hline \multirow[t]{4}{*}{$\begin{array}{l}\text { Teaching } \\
\text { presence }\end{array}$} & Min & 2 & 2 & 2 \\
\hline & Max & 5 & 5 & 5 \\
\hline & Mean & 3.98 & 4.14 & 4.20 \\
\hline & Std.D & 0.59 & 0.56 & 0.53 \\
\hline \multirow[t]{4}{*}{$\begin{array}{c}\text { Social } \\
\text { presence }\end{array}$} & Min & 1 & 2 & 2 \\
\hline & Max & 5 & 5 & 5 \\
\hline & Mean & 3.78 & 3.85 & 3.94 \\
\hline & Std.D & 0.59 & 0.57 & 0.58 \\
\hline \multirow[t]{4}{*}{$\begin{array}{c}\text { Global } \\
\text { CoI }\end{array}$} & Min & 2 & 2 & 2 \\
\hline & Max & 5 & 5 & 5 \\
\hline & Mean & 3.87 & 3.99 & 4.06 \\
\hline & Std.D & 0.53 & 0.50 & 0.49 \\
\hline
\end{tabular}

Teaching Presence $\left(\chi^{2}=11.176, \mathrm{p}<0.01\right)$, in the Cognitive Presence $\left(\chi^{2}=6.898, \mathrm{p}<0.05\right)$, but did not differ from the others in the Social Presence.

Oddly, when we compare students by gender through the Mann-Whitney $U$ test, only in Teaching Presence did the girls exceed their male colleges $(U=25502.500, p<0.05)$, similarly to the Cognitive and Social Presences.

In order to portray the frequency and typology of the discussion developed in the curricular units previously referred, we present, by means of a social network analysis diagram, a brief description of the forum interactions.

\section{What the SLCS Reveals about the Self-Learning Skills}

As can be seen in Table 4, the Self-Learning Competence Scale (SLCS) showed good internal consistency with a value of 0.948, while the various dimensions: 1) Active Learning or Accepting Personal Responsibility through Learning; 2) Learning Initiative and Guidance to Experience; and 3) Learning Autonomy, show values of $0.902,0.814$ and 0.818 , respect tively. Assuming that an instrument with an internal consistency of 0.70 (Cronbach, 1984; Nunnally, 1978) can be considered fit to evaluate the variable to be measured (although, desirably, the alpha should be above 0.80 ), we believed that the instrument showed coefficients with very adequate internal consistency.

The correlation between the different sub-scales is also significant $(p<0.01)$, which shows the consistency of the scale in its entirety (see Table 5).
Table 4.

Analysis of internal consistency-Cronbach's Alpha.

\begin{tabular}{ccc}
\hline & Cronbach's Alpha & No. of Items \\
\hline ECAA & 0.948 & 24 \\
1 & 0.902 & 12 \\
2 & 0.814 & 6 \\
3 & 0.818 & 6 \\
\hline
\end{tabular}

In the descriptive analysis, we have highlighted the central tendency (mean) and the mean deviation as a measure of dispersion, the minimum and maximum scale value in the answers given. Table 6 shows these values for each sub-scale.

The results show that the study participants used all points on the scale, clearly expressing positive views on their learning competences, with central values very close to 4 , showing a positive impact of online environments on the promotion of competences in terms of active learning, initiative or learning autonomy.

For the comparative analysis of the sub-cohort of participants as regards gender and institutional origin of the training institution, we used a non-parametric statistics using the Mann-Whitney test (Marôco, 2007). Despite the robustness of parametric tests and the size of the cohort $(\mathrm{N}>30)$, distributions are not symmetrical or mesocurtical. On the other hand, no previous studies were found in online environments to allow us to assume that the variables under analysis would meet the requirements of normality in the population in question.

In the hypothesis tests for the differences, we found that, according to gender, the distribution of results in any of the subscales did not differ, and the perception of self-learning is common for both boys and girls.

However, when groups were compared on the basis of their institutional origin, on all three sub-scales, students from polytechnic institutions show more favourable means, and they differ significantly from the university participants in the study as regards all three sub-scales (see Table 7).

\section{Conclusion}

Considering the axiomatic paradigm of education as a relationship, the proximity between teacher and students and among students, jeopardized by the loss of the status quo of each of the participants in the classroom open to everyone, seems to be recovered by the online learning process. In fact, the results obtained in this study show the relevance of the community of inquiry and their invaluable potential to promote competences in terms of active learning, initiative or learning autonomy.

Indeed, regardless of the course and type of institution, we have found that either group is constituted as a community in all indicators. However, although they all perceive a strong social presence when the learning process is guided by web mediation, the study showed that he groups under analysis differ in how they view the cognitive effects and the presence of teaching. In particular, we found that polytechnic students attending health and education courses, in the current context, are positively different when compared to university students attending 
Table 5.

Correlations between SLCS sub-scales.

\begin{tabular}{cccc}
\hline & $\begin{array}{c}\text { Mean } \\
\text { 1) }\end{array}$ & $\begin{array}{c}\text { Mean } \\
\text { 2) }\end{array}$ & $\begin{array}{c}\text { Mean } \\
3)\end{array}$ \\
\hline Mean 1) & 1 & 12 & \\
Mean 2) & $0.869^{* *}$ & 1 & \\
Mean 3) & $0.846^{* *}$ & $0.842^{* *}$ & 1 \\
\hline
\end{tabular}

Table 6.

Descriptives statistics for each SLCS dimension.

\begin{tabular}{ccccc}
\hline SLCS & Min. & Max. & Mean & $\begin{array}{c}\text { Standard } \\
\text { deviation }\end{array}$ \\
\hline 1$)$ & 1 & 5 & 3.9143 & 0.53486 \\
$2)$ & 1 & 5 & 3.9110 & 0.53791 \\
$3)$ & 1 & 5 & 3.7575 & 0.62576 \\
\hline
\end{tabular}

the psychology courses, which emerge as a less robust online community.

Since we wanted to understand why they differed, we monitored some virtual classrooms using the SNAPP software and the Netdraw to analyze the data, we concluded that the differences could be related to how teachers assumed different roles in online discussions. Whereas in the virtual classrooms of polytechnic students the discussions were teacher-centered, in the university student group the discussions were shared by all network members, and the teacher assumed a more peripheral stance. This enabled university students to create small interaction networks between its members and to be more autonomous. That is, it appears that the teacher in this group assumed a mediating role, encouraging students to look for information, helping them to reflect on the processes needed to grasp formal concepts. More than imparting knowledge, this teacher sought to guide the learning process by helping students to develop their ability to learn single handedly. While bearing in mind these principles, it seems also the teachers of other groups assumed a more interventive attitude in virtual classroom discussions, controlling the process through dialogue and systematic mediation, which fostered a positive human interaction between the teacher and the learners, not only in terms of cognition but also in terms of emotions.

It is also interesting to note that the results of girls were higher than those of boys in all presences considered, and that their sense of community is significantly superior in the teacher's presence. In order to understand these results, we also monitored some virtual classrooms with the SNAPP software and found that the girls participated more effectively in the discussions, which shows the decisive role they had in the consolidation of social-communicative and social-educational relations that were established in these communities. In this respect, we believe that the variables of social-psychological circum stances and the emotional aspects, related to their motivation, satisfaction, imagination and creativity may explain these results.

We, also, concluded that the strategies and methods adopted in the different schools, favoring work attitudes and collabora-
Table 7.

Mann-Whitney's U test on the basis of training institution.

\begin{tabular}{cccc}
\hline & SLCS 1) & SLCS 2) & SLCS 3) \\
\hline University & $3.8(0.60)$ & $3.8(0.58)$ & $3.6(0.65)$ \\
Polytechnic & $4.0(0.44)$ & $4.0(0.45)$ & $3.8(0.57)$ \\
$U$ & 7757.5 & 7511.5 & 7487.5 \\
$P$ & 0.006 & 0.002 & 0.001 \\
\hline
\end{tabular}

tive learning, clearly showed that the online environment, whose design focuses on the development of competences had very positive effects on how students view learning competences, according to the three considered dimensions: Active Learning and Accepting Personal Responsibility through Learning, Learning initiative and Guidance to Experience, and Learning Autonomy. Regarding the differences between public and private education, we concluded that there are significant differences in perceiving the ability to learn actively and accepting responsibility through learning, as well as in the learning initiative and guidance to experience, where private education students are at a clear vantage point. These more favourable results for private education students may be related to the greater experience of their teacher, who is clearly more at ease in these environments, while the public education teacher is less experienced in e-learning modalities. Besides the influence of teachers, we have to take into consideration the different training culture of both types of institutions.

Based on this data, we can conclude that it is increasingly important to structure balanced relationships between social, cognitive and teaching presences in order to provide significant educational experiences.

In this sense, each community of inquiry of Portuguese higher education students must be structured focusing specifically on what must be learned and the learning outcomes. Moreover, teachers as tutors must explain how students will learn to learn, directing the instruction to heuristic procedures, including self-assessment, so that students are aware of their sustained and systematic cognitive construction. The opportunities of online learning are of paramount importance to allow for convergence and provide benefits for all, so that the supply of higher education can be an ongoing construction of all for all, safe and with quality.

We need to emphasize that given their limitations these results should be interpreted with caution. Like any other work, ours also has limitations, some of which we recognize immediately, for e.g., external validity, since the results cannot be understood as final and overall applicable. Indeed, note that the empirical component of research is quantitative, resulting from the quasi-experimental plan, because we our study consists of about 500 public and private, polytechnic and university higher education, already placed in classrooms, but not randomly, drawn from what Moore (1983) called experimentally accessible population.

Our intention is to do justice to the theme, due to its relevance and the impact it deserves in practical terms. In our opinion, this work cannot be seen as completed, but it should rather assume an instrumental nature, useful for those who want to make use of it as a consultation or critique instrument, or 
even as a starting point for other pragmatically valid work, in order to enrich the range of contributions to understand the issues on the agenda.

\section{REFERENCES}

Alonso, G., Manrique, D., \& Viñes, J. M. (2005). An instructional model for web-based e-learning education with a blended learning process approach. British Journl of Educational Technology, 36, 217-235. doi:10.1111/j.1467-8535.2005.00454.x

Arbaugh, J. B., Cleveland-Innes, M., Diaz, S. R., Garrison, D. R., Ice, P., Richardson, J. C., \& Swan, K. P. (2008). Developing a community of inquiry instrument: Testing a measure of the community of inquiry framework using a multi-institutional sample. Internet and Higher Education, 11, 133-136. doi:10.1016/j.iheduc.2008.06.003

Cronbach, L. (1984). Essencial of psychological testing. New York: Harper e Row.

European Network of Information Centres in the European Region \& National Academic Recognition and Information Centres in the European Union (2010). TUNING guide to formulating degree programme profiles, including programme competences and programme learning outcomes.

http://www.unideusto.org/tuningeu/news/289-recently-published-deg ree-programme-profiles.html

Faria, L., Rurato, P., \& Lima Santos, N. (2000). Papel do auto-conceito de competência cognitiva e da auto-aprendizagem em contexto sócio-laboral. Análise Psicológica, 2, 203-219.

Garrison, D. R., \& Anderson, T. (2003). E-learning in the 21 st century. London: Routledge Falmer. doi:10.4324/9780203166093

Garrison, D. R, Anderson, T., \& Archer, W. (2000). Critical Inquiry in a text-based environment: Computer conferencing in higher education. The Internet and Higher Education, 2, 87-105. doi:10.1016/S1096-7516(00)00016-6

Jonassen, D. (1999). Designing constructivist learning environments. In C. Reigeluth, (Ed.), Instructional-design theories and models: A new paradigm of instructional theory (pp. 215-239). University Park: Pennsylvania State University.

Lima Santos, N., Rurato, P., \& Faria, L. (2000). Auto-aprendizagem e auto-conceito de competência em contexto empresarial. Psicologia: Teoria, Investigação e Prática, 1, 135-146.

Lima Santos, N., \& Gomes, I. (2009). Transformações e tendências do ensino-aprendizagem na era do digital: alguns passos para uma arqueologia de um novo saber-poder. Revista antropológicas, 11, 143159.

Magalhães, M. (2011). Autoconceito de competência e autoaprendizagem em alunos do ensino secundário: Comparação de cursos científico-humanísticos com cursos profissionais. Master Thesis. Porto: University Fernando Pessoa.
Marôco, J. (2007). Análise estatística com utilização do SPSS. Lisboa: Edições Sílabo.

Monteiro, A. (2011) O currículo e a prática pedagógica com recurso ao b-learning no ensino superior. Ph.D. Thesis, Porto: Porto University.

Moore, W. (1983). Developing and evaluating educational research. Boston: Little Brown and Company.

Moreira, J. A., \& Monteiro, A. (2010). O Trabalho Pedagógico em Cenários Presenciais e Virtuais no Ensino Superior. Educação, Formação e Tecnologia, 3, 82-94. http://eft.educom.pt

Moreira, J. A., \& Almeida, A. C. (2011). How reliable and consistent is our learning community of inquiry? Psychometric qualities of the community of inquiry survey instrument applied to a sample of higher education portuguese students. Proceedings of the Internacional Conference on Education and New Learning Technologies, Barcelona, 4261-4267.

Netdraw. http://www.analytictech.com/

Nyhan, B. (1996). Desenvolver a capacidade de aprendizagem das pesos-as: Perspectivas europeias sobre a competência de auto-aprendizagem e mudança tecnológica. Caldas da Rainha: Eurotecnet.

Nunnaly, J. (1978). Psychometric theory. New York: McGraw-Hill.

Parlamento Europeu e Conselho da União Europeia (2006). Recomendação do Parlamento Europeu e do Conselho, de 18 de Dezembro de 2006, sobre as competências essenciais para a aprendizagem ao longo da vida, 10-18.

Perret-Clermont, A. (1996). Desenvolvimento da Inteligência e Interacção Social. Lisboa: Instituto Piaget.

Rurato, P. (2008). As Características dos Aprendentes na Educação a Distância-Impacto no Processo Educativo com vista ao Desenvolvimento de Estratégias de Sucesso. Ph.D. Thesis. Aveiro: Aveiro University.

SNAPP Social networks adapting pedagogical practice. http://research.uow.edu.au/learningnetworks/seeing/snapp/index.html

Swan, K., Shea, P., Richardson, J., Ice, P., Garrison, D. R., ClevelandInnes, M., et al. (2008). Validating a measurement tool of presence in online communities of inquiry. E-Mentor, 2, 1-12.

http://www.ementor.edu.pl/e_index.php?numer=24\&all=1

Thompson, T. L., \& Macdonald, C. J. (2005). Community building, emergent design and expecting the unexpected: Creating a quality e-Learning experience. Internet and Higher Education, 8, 233-249. doi:10.1016/j.iheduc.2005.06.004

Vaughan, N., \& Garrison, D. R. (2005). Creating cognitive presence in a blended faculty development community. The Internet and Higher Education, 8, 1-12.

White, B. Y., \& Frederiksen, J. R. (1998). Inquiry, modeling, and metacognition: Making science accessible to all students. Cognition and Instruction, 16, 3-118. 